\title{
Mancha bacteriana em Ruscus sp. causada por Burkholderia andropogonis no Brasil
}

\author{
Irene M.G. Almeida ${ }^{1}$, Luís O.S. Beriam¹ ${ }^{1}$ Ana M. Sannazzaro ${ }^{2} \&$ Júlio Rodrigues Neto $^{1}$ \\ ${ }^{1}$ Instituto Biológico, 13012-970, Campinas, SP, Brasil; ${ }^{2}$ Agência Paulista Tecnologia Agronegócio - APTA, Unidade de \\ Pesquisa de Desenvolvimento Sorocaba, 18013-440, Sorocaba, SP, Brasil
}

Autor para correspondência: Irene M.G. Almeida, e-mail: gatti@biologico.sp.gov.br

\section{RESUMO}

Em abril de 2008 foram recebidas folhas de Ruscus sp. originárias de plantios localizados na região de Santo Antonio de Posse SP com sintomas de manchas arredondadas, com 5 a $8 \mathrm{~mm}$ de diâmetro, de coloração marrom escura, com centro necrótico e circundadas por halo clorótico. Dos isolamentos realizados, foram obtidas colônias bacterianas de cor creme, de crescimento lento, com células Gramnegativas, oxidativas e não fluorescentes. Inoculações artificiais em Ruscus sp. reproduziram os sintomas observados nas infecções naturais. Testes bioquímicos, culturais e serológicos permitiram identificar o patógeno como Burkholderia andropogonis (sin. Pseudomonas andropogonis). Este é o primeiro relato dessa espécie bacteriana em Ruscus sp. no Brasil. Linhagens bacterianas encontram-se depositadas na Coleção de Culturas de Fitobactérias do Instituto Biológico (IBSBF) sob nos. 2594 e 2595.

Palavras-chave: Pseudomonas andropogonis, etiologia, diagnose, plantas ornamentais.

\begin{abstract}
Bacterial leaf spot on Ruscus sp. caused by Burkholderia andropogonis in Brazil

Plants of ruscus (Ruscus sp.) showing symptoms of leaf spot were received for analysis in April 2008 from a field located in the region of Santo Antonio de Posse, state of São Paulo, Brazil. These spots were small, rounded, with 5 to 8 mm in diameter, dark brown in color, showing necrotic center and surrounded by chlorotic haloes. Slow-growing, cream-colored bacterial colonies were consistently obtained. The bacterium was Gram-negative, oxidative and not fluorescent. Artificial inoculations on healthy ruscus seedlings reproduced the symptoms observed in natural infections; the pathogen was re-isolated from the lesions. Biochemical, cultural, physiological and serological tests of the isolates identified the causal agent as Burkholderia andropogonis (former Pseudomonas andropogonis). This is the first report of this pathogen in ruscus in Brazil. Bacterial strains were deposited in the Phytobacteria Culture Collection of the Instituto Biológico (IBSBF) under numbers 2594 and 2595.
\end{abstract}

Keywords: Pseudomonas andropogonis, etiology, diagnosis, ornamental plants.

Ruscus sp. é uma planta ornamental da família Ruscaceae, originária do sul e oeste europeu, com folhas lisas, verde escuras, sem espinhos, apresentando estruturas denominadas cladódios, que são caules modificados. É uma planta utilizada em arranjos florais, podendo também ter o papel de "enchimento" em decorações. São usadas na forma seca ou ramos recém colhidos, sendo extremamente duráveis (Stamp, 2001). Em abril de 2008, amostras de ramos de Ruscus sp. com sintomas de manchas foliares, originários de plantios localizados na região de Santo Antonio da Posse SP, foram recebidas para análise no Laboratório de Bacteriologia Vegetal do Instituto Biológico. Essas manchas eram arredondadas, com 5 a $8 \mathrm{~mm}$ de diâmetro, de coloração marrom escura, apresentando centros necróticos e circundadas por halos cloróticos (Figura 1). Observações ao microscópio óptico de pequenas porções dos tecidos foliares com tais sintomas mostraram intensa exsudação bacteriana. Isolamentos realizados em meio nutriente-ágar (Levine, 1954) apresentaram, após $48-72$ horas de incubação a $28^{\circ} \mathrm{C}$, colônias bacterianas de cor creme, de crescimento lento em meio de cultura e que mostravam aderência ao meio com o envelhecimento da colônia. As bactérias eram Gramnegativas, oxidativas, oxidase negativas, não produtoras de pigmento fluorescente quando cultivadas em meio B de King, negativas para reação de hipersensibilidade em folhas de fumo, indicando tratar-se de Burkholderia andropogonis (Smith 1911) Gillis et al. 1995 (sinônimo: Pseudomonas andropogonis).

Para comprovar a patogenicidade dos isolados, foram feitas inoculações artificiais por aspersão de suspensão bacteriana em água destilada esterilizada (ca. $10^{8}$ UFC $\mathrm{mL}^{-1}$ ) em folhas de mudas sadias de Ruscus sp., previamente feridas com agulha esterilizada. Paralelamente, foram também inoculadas cinco plantas de café cv. Mundo Novo, com quatro meses de idade e cinco plantas de milho doce híbrido cv. AG1051. com 20 dias de idade, ambos hospedeiros de B. andropogonis (Bagsic et al., 1995), utilizando-se a mesma metodologia. Nas 

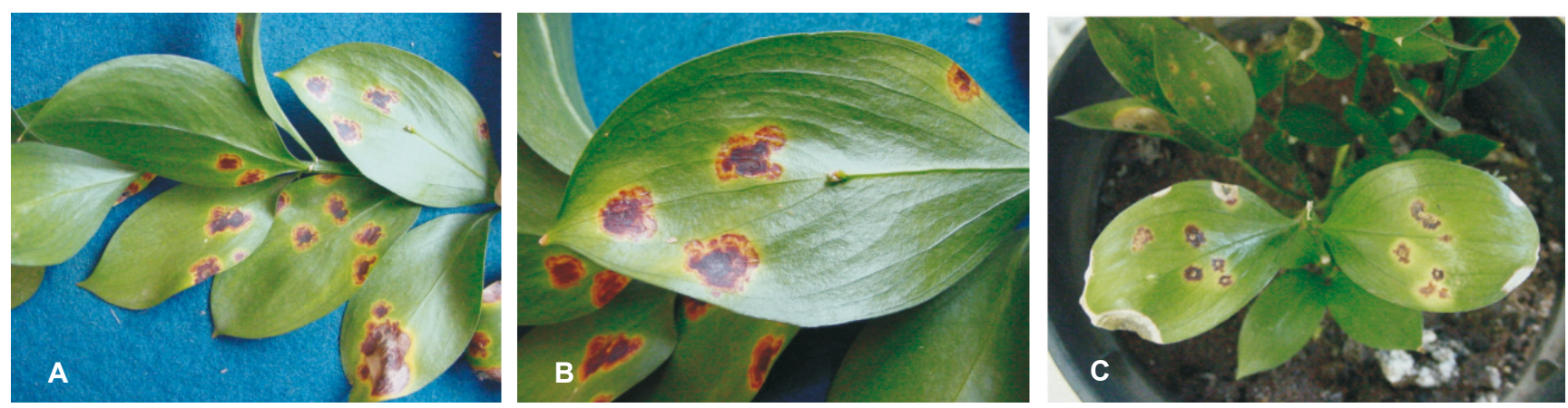

FIGURA 1 - Sintomas de mancha bacteriana em folhas de Ruscus sp., causadas por Burkholderia andropogonis. A. em condições de campo; B. detalhe das lesões; C. após inoculação artificial.

plantas testemunhas, o inóculo foi substituído por água esterilizada. As plantas inoculadas foram mantidas em condições de câmara úmida por 72 horas. Cinco isolados foram caracterizados por meio de testes bioquímicos, culturais, fisiológicos, segundo Bradbury (1986) e Schaad et al. (2001). Também foi realizada a caracterização por meio de testes serológicos de dupla difusão em ágar (dda) (Ouchterlony, 1958), utilizando-se antissoro contra linhagem de Burkholderia andropogonis originária de trevo (Trifolium repens), pertecente à Soroteca do Laboratório de Bacteriologia Vegetal, Instituto Biológico.

As inoculações artificiais em mudas de Ruscus sp. reproduziram os sintomas originalmente observados (Figura 1), e o patógeno foi reisolado e comparado com os isolados originais, completando-se, desta maneira, os Postulados de Koch. As plantas de café e de milho não apresentaram nenhum tipo de sintoma. Os testes bioquímicos (Tabela 1) permitiram identificar as linhagens bacterianas como B. andropogonis. Esses resultados foram corroborados pelas reações serológicas (dda), nas quais foi observada identidade total entre as suspensões bacterianas dos isolados de Ruscus sp. e o antissoro contra a bactéria. $B$. andropogonis apresenta um grande número de plantas hospedeiras, algumas de importância econômica, incluindo 15 famílias e 51 espécies entre mono e dicotiledôneas. Esse patógeno se apresenta amplamente distribuído em diversas regiões da África, Ásia, Austrália, Oceania, Europa e Américas do Norte e do Sul (Bagsic et al., 1995).

Essa espécie bacteriana apresenta relativa homogeneidade com relação à filogenia e características fenotípicas, mas grande diversidade genética entre isolados, sem que tenha sido observada correlação entre hospedeiro, localização geográfica e patogenicidade (Bagsic et al., 1995; Bagsic-Opulencia et al., 2001). No Brasil, esta bactéria já foi descrita causando danos em primavera (Bougainvillea sp.), café (Coffea arabica), cravo (Dianthus caryophyllus), mucuna (Mucuna pruriens), pau-ferro (Chamaecrista ensiformes), sorgo (Sorghum bicolor), trapoeraba (Tradescantiafluminensis) e em triplaris (Triplaris filipensis) (Malavolta Jr. et al., 2008). Em Ruscus sp., a bactéria já foi assinalada nos Estados Unidos, causando perdas na cultura desde 1989, apresentando sintomas severos quando as plantas se encontram expostas a condições de chuva e irrigação inadequadas (Chase, 2007). Mais recentemente, este patógeno também foi descrito na Austrália causando sintomas necróticos, com anasarca, circundados por halos cloróticos em plantas de Dypsis lutescens, pertencente à família Arecaceae (Young et al., 2007) e em plantas de jojoba (Simmondsia chinensis) (Cother et al., 2004) e também em Taiwan causando danos em palmeira betel (Areca catechu) (Hseu et al., 2007).

Segundo Palleroni (1984), a diversidade patogênica de $B$. andropogonis evidencia uma especialização das linhagens a determinados hospedeiros, sugerindo a ocorrência de patovares nesta espécie. Entretanto, Moffett et al. (1986) afirmam que as diferenças em especificidade a hospedeiros não são suficientes para o estabelecimento de patovares nessa espécie bacteriana. Embora os estudos realizados por Robbs et al. (1982), Gitaitis et al. (1983), Cother et al. (2004) e Takahashi et al. (2004) demonstrem que determinadas linhagens de $B$. andropogonis infectam espécies diferentes de plantas, a especialização patogênica não parece estar limitada a determinadas regiões, provavelmente devido ao intercâmbio de materiais vegetais de propagação. Isso provavelmente seja o motivo pelo qual os isolados de Ruscus sp. não se mostraram patogênicos quando inoculados em mudas de milho e de cafeeiro.

Com relação ao controle da doença, estudos realizados por Chase \& Stamps (1992) mostraram que compostos cúpricos não foram eficazes no controle da doença durante os meses de maior severidade. De acordo com Chase (2007), a mais importante medida de controle é o plantio de mudas de matrizes sabidamente sadias. Por se tratar de doença de parte aérea, deve-se evitar a irrigação por aspersão, que facilita a disseminação do patógeno e, sempre que possível, o adensamento entre plantas, para permitir melhor circulação do ar entre elas. Trata-se do primeiro relato desse patógeno em plantas de Ruscus sp. em nosso país. Linhagens bacterianas estão depositadas na Coleção de Culturas de Fitobactérias do Instituto Biológico (IBSBF) sob números 2594 e 2595. 
TABELA 1 - Características bioquímicas, culturais e fisiológicas do isolado de Ruscus sp. e de Burkholderia andropogonis

\begin{tabular}{|c|c|c|}
\hline \multirow{2}{*}{ Características observadas } & \multicolumn{2}{|c|}{ Bactérias } \\
\hline & $\begin{array}{l}\text { Isolado de } \\
\text { Ruscus sp. }\end{array}$ & B. andropogonis ${ }^{2}$ \\
\hline Gram & -1 & - \\
\hline $\mathrm{O} / \mathrm{F}$ glicose & oxidativo & oxidativo \\
\hline Oxidase & - & - \\
\hline Arginim di-hidrolase & - & - \\
\hline Hipersensibilidade em fumo & - & - \\
\hline $\begin{array}{l}\text { Produção de ácidos dos carbohidratos: } \\
\text { arabinose, frutose }\end{array}$ & + & + \\
\hline galactose, manitol & + & + \\
\hline manose, D-sorbitol & + & + \\
\hline celobiose, eritritol, maltose & - & - \\
\hline sacarose, salicina & - & - \\
\hline $\begin{array}{l}\text { Utilização de ácidos a partir dos sais sódicos: } \\
\text { citrato, malonato, succinato }\end{array}$ & + & + \\
\hline acetato, oxalato & - & - \\
\hline Redução de $\mathrm{NO}_{3}$ a NO & - & - \\
\hline Hidrólise de gelatina & - & - \\
\hline Produção de urease & + & + \\
\hline Produção de pigmento fluorescente em meio BK & - & - \\
\hline
\end{tabular}

\section{REFERÊNCIAS BIBLIOGRÁFICAS}

Bagsic RD, Fegan M, Li X, Hayward AC (1995) Construction of species-specific primers for Pseudomonas andropogonis based on 16S rDNA sequences. Letters in Applied Microbiology 21:87-92.

Bagsic-Opulencia RD, Hayward AC, Fegan M (2001) Use of ribotyping and random amplified polymorphic DNA to differentiate isolates of Burkholderia andropogonis. Journal of Applied Microbiology 91:686-696.

Bradbury JF (1986) Guide to plant pathogenic bacteria. Kew. CAB International.

Chase AR (2007) Pseudomonas leaf spot of ruscus. Disponível em: <http://mrec.ifas.ufl.edu/Foliage/Resrpts/rh_93_16.htm>. Acesso em: 13 mar 2007.

Chase AR, Stamps RH (1992) Copper compounds do not provide adequate Pseudomonas control on Ruscus. Cut Foliage Grower 7:1-3.

Cother J, Noble D, Peters J, Abiston A, Ash GJ (2004) A new bacterial disease of jojoba (Simmondsia chinensis) caused by Burkholderia andropogonis. Plant Pathology 53:129-135.

Gitaitis RD, Miller J, Wells HD (1983) Bacterial leaf spot of clover in Georgia. Plant Disease 67:913-914.

Hseu SH, Lai WC, Pan YP, Lin CY (2007) Occurrence of bacterial leaf spot of betel palms caused by Burkholderia andropogonis and inhibition of bacterial growth by agrochemicals. Plant Pathology Bulletin 16:131-139.
Levine M (1954) An introduction to laboratory technique in bacteriology. New York NY. Mac Millan. pp. 68-79.

Malavolta Jr. VA, Beriam LOS, Almeida IMG, Rodrigues Neto J, Robbs CF (2008) Bactérias fitopatogênicas assinaladas no Brasil: uma atualização. Summa Phytopathologica 34:1-88. (Suplemento Especial)

Moffet ML, Hayward AC, Fahy P (1986) Five new hosts of Pseudomonas andropogonis occurring in eastern Australia: host range and characterization of isolates. Plant Pathology 35:34-43.

Ouchterlony O (1958) Diffusion-in-gel methods for immunological analysis. Progress in Allergy 5:1-78.

Palleroni NJ (1984). Genus I Pseudomonas Migula 1894. In: Krieg NR, Holt JG (Eds.) Bergey's Manual of Systematic Bacteriology. Baltimore MD. Williams \& Wilkins. pp. 141-199.

Robbs CF, Rodrigues Neto J, Ribeiro RLD, Kimura O (1982) Bacterial leaf spot of ornamental triplaris caused by Pseudomonas andropogonis. Proceedings of the Fifth International Conference on Plant Pathogenic Bacteria. Cali, Colômbia. pp. 54-59.

Schaad NW, Jones JB, Chun W (Eds.) (2001) Laboratory guide for identification of plant pathogenic bacteria. $3^{\text {rd }}$ ed. Saint Paul MN. APS Press.

Stamp RH (2001) Florida/Holland/Israeli ruscus production and use. Institute of Food and Agricultural Sciences, University of Florida. Circular 1268 (ENH 844). Disponível em: <http://edis. ufl.edu>. Acesso em: 13 mar 2007. 
I.M.G. Almeida et al.

Takahashi Y, Takahashi K, Watababe K, Kawano T (2004) Bacterial black spot caused by Burkholderia andropogonis on Odontoglossum and intergeneric hybrid orchids. Journal of General Plant Pathology 70:284-287.
Young AJ, Grice KRE, Trevorrow PR, Vawdrey LL (2007)

Burkholderia andropogonis blight of golden cane palms in north Queensland. Australasian Plant Disease Notes 2:131-132.

TPP 9007 - Recebido 16 Janeiro 2009 - Aceito 27 Agosto 2009 Editor de Seção: Marisa A.S.V. Ferreira 